\title{
Cattaneo -Christov heat flux model for magnetohydrodynamic flow in a suspension of dust particles towards a stretching sheet
}

https://doi.org/10.1515/nleng-2017-0162

Received November 18, 2017; revised December 7, 2017; accepted December 29, 2018.

\begin{abstract}
In the present paper, the flow of an incompressible, electrically conducting dusty fluid over a stretching sheet is considered. The Cattaneo- Christov heat flux theory is employed to control the thermal boundary layer. The flow equations are transformed into nonlinear ordinary differential equations (NODEs) and which are solved with help of Runge-Kutta $4^{\text {th }}$ order method. Flow equations are examined with respect to boundary conditions namely prescribed wall temperature (PWT) and prescribed heat flux (PHF) cases. In general PWT and PHF boundary conditions are very useful in the industrial as well as manufacturing up and down processes. Impact of the emerging parameters on the dimensionless velocity and temperature as well as friction coefficient and local Nusselt number are examined. We also validated my results with already available literature. It is found that the heat transfer rate of the flow in PWT case is higher than that of PHF case. These results can help us to conclude that for higher heating processes (Heating industries) PWT case and lesser heating processes (Cooling industries) PHF boundary condition is useful.
\end{abstract}

Keywords: PWT and PHF Case, Cattaneo-Christov heat flux model, MHD, Dusty fluid

S. Mamatha Upadhya, Department of Mathematics, Garden City College of Science and Management Studies, $16^{\text {th }} \mathrm{KM}$,Old Madras Road, Bangalore 560049, Karnataka, India, E-mail: mamathasupadhya@gmail.com

Mahesha, Department of Mathematics, University B.D.T. College of Engineering, Davangere-577004, India, E-mail: maheshubdt@gmail.com

*Corresponding Author: C.S.K. Raju, Department of Mathematics, GITAM University, Bangalore, Karnatak, India, E-mail: sivaphd90@gmail.com

\section{Introduction}

One of the most important areas of engineering practice lies in studying the flow and heat transfer of fluid towards a stretching sheet, since it has numerous applications. The impact of heat transfer is seen in the field of metallurgy and chemical engineering, polymer processing, food stuff processing manufacturing of artificial films, aerodynamics extrusion of plastic sheets, glass fiber production, hot rolling, metal extrusion, metal spinning, paper production, drawing of plastic films and wires. The outcome in this process depends on the heat transfer rate; hence a wide range of work has been done on boundary layer flow of Newtonian and non-Newtonian fluids over linear and non-linear stretching sheet. Starting from the primary work of sakiadis [1] numerous features of heat transfer and momentum over a stretching sheet have been studied. Crane [2] examined the exponential solution for the flow caused by the stretching sheet and he also gave an exact solution for the flow field. Eldahad and Aziz [3] analyzed the effect of non-uniform heat source with suction/blowing in the case of viscous fluid. Saffman [4] proposed governing equations for the flow of dusty fluid. Datta and Mishra [5] studied the problem of laminar two phase boundary layer on a semi-infinite flat plate. Agranat [6] examined the effect of dustiness and pressure gradient on the friction and heat transfer Co-efficient. Vajravelu and Nayfeh [7] have analyzed the behavior of hydro magnetic flow of a dusty fluid over a stretching sheet with the effect of suction. Grubka and Bobba [8] investigated the effect of power Law surface temperature variation on the heat transfer characteristics of a continuous, linearly stretching surface with variable temperature. Chamkha [9] studied the convective heat and mass transfer past a semi- Infinite vertical permeable moving plate with absorption of heat. Aziz [10] has presented the numerical solution for laminar thermal boundary over a flat plate with convective surface boundary conditions using the symbolic algebra software Maple. Hermann Schlichting [11] has explained boundary layer heat transport equations in the presence of nonuniform internal heat generation and absorption for two 
dimensional flows. Abel and Mahesha [12] have reported an analytical and numerical solution for the heat transfer in a study laminar flow of an incompressible viscoelastic fluid over a stretching sheet with power law surface temperature. Raju et al. [13] discussed the non-Newtonian flow over cone with non-uniform heat source/sink. Ezzat et al. [14] examined space approach to the hydro magnetic flow a dusty fluid through a porous medium. Raju et al. [15] explored the effects of non-uniform on magnetohydrodynamic flow over an exponentially stretching sheet. Gireesha et al. [16-20] have explored the boundary layer flow and heat transfer of a dusty fluid with several aspects. Recently, Siddiqa et al. [21] have considered two-phase natural convection flow of a dusty fluid namely water-metal mixture, oil metal mixture and air metal mixture. Ramesh et al. [22, 23] have examined heat transfer characteristics using the Roseland approximation for the model stagnation point flow of a MHD dusty fluid towards a stretching sheet with radiation and have studied boundary layer flow past a stretching sheet with fluid practical suspension and convective boundary condition they found that the temperature of both fluid and dust phase increases with increasing Biot number. The magnetohydrodynamic flow over cone with dust and non-Newtonian fluids was investigated by Raju et al. [24] and Sugunamma et al. [25]. With that they concluded that magnetic field parameter controls the velocity field.

To analyze the heat transfer phenomenon many researchers used heat conduction law suggested by Fourier [26]. Later this model was enhanced by Cattaneo [27] with the insertion of relaxation time for heat flux. Further, Christov [28] introduced a derivative model of Cattaneo's law and that became prominent as CattaneoChristov heat flux. This heat flux model has important applications in Bio medical and industries e.g. nuclear reactor cooling, hybrid power generators, heat conduction in tissues pasteurization of milk, magnetic drug targeting, electronic devices. On basis of these application Han et al. [29] used Cattaneo-Christov heat flux model to investigate the slip flow and heat transfer of Maxwell fluid bounded by a stretching sheet. Junaid Ahmad Khan et al. [30] has explored that fluid temperature has inverse relationship with the thermal relaxation time by using Cattaneo-Christov heat flux model for viscoelastic flow due to an exponentially stretching sheet.

In this paper we intend to study the boundary layer flow of an incompressible viscous electrically conducting dusty fluid towards stretching sheet using CattaneoChristov heat flux model. We are considering Heat transfer characteristics with respect to different kinds of boundary heating namely the sheet with prescribed surface temper- ature (PST case) and the sheet with prescribed wall heat flux (PHF). The transformed governing boundary layer equations are solved numerically using Runge-Kutta based shooting technique. The behaviors of various parameters on the physical quantities of interest are examined and shown in graphs and tables.

\section{Mathematical Formulation}

\subsection{Flow Analysis}

In the present analysis, we consider the flow of an electrically conducting dusty fluid which is incompressible viscous in nature with an electrical conductivity over a linearly stretching sheet. The flow is two dimensional where stretching surface is chosen along the $\mathrm{x}$-axis and $\mathrm{y}$-axis is normal to it flow is assumed to be confined with respect to the region $y>0$. The sheet is stretched by keeping origin fixed and applying two equal and opposite forces along the $x$-axis. A magnetic field of uniform strength $B_{0}$ is applied along the y-axis. The fluid is assumed to be Newtonian and its properties are constant and the chemical reaction is assumed to take place during the flow. The volume fraction and interparticle collision of dust particles are assumed to be negligible. The induced magnetic field is neglected by considering the Reynolds number to be small .It is assumed that dust particles are uniformly distributed throughout the fluid, equal in size and has spherical shape. Only because of drag force there is interaction, heat and mass transfer between the fluid and dust phases. To model the drag force stokes linear drag concept is employed. $\mathrm{U}_{w}(\mathrm{x})=\mathrm{ax}$ is the stretching sheet velocity where as $\mathrm{a}>0$ is the stretching rate, $\mathrm{T}_{w}$ represents the temperature of the fluid at the sheet whereas $\mathrm{T}_{\infty}$ the ambient temperature so that $\mathrm{T}_{w}>\mathrm{T}_{\infty}$. In view of the above assumptions, the boundary layer flow along stretching sheet describing the conservation of mass and momentum for both clean fluid and dusty fluid can be expressed as follows [7, 23]:

$$
\begin{gathered}
\frac{\partial u}{\partial x}+\frac{\partial v}{\partial y}=0 \\
\rho\left(u \frac{\partial u}{\partial x}+v \frac{\partial u}{\partial y}\right)=\mu \frac{\partial^{2} u}{\partial y^{2}}-\frac{d p}{d x}+K N\left(u_{p}-u\right)-\sigma B_{0}^{2} u \\
u_{p} \frac{\partial u_{p}}{\partial x}+v_{p} \frac{\partial u_{p}}{\partial y}=\frac{k}{m}\left(u-u_{p}\right) \\
u_{p} \frac{\partial v_{p}}{\partial x}+v_{p} \frac{\partial v_{p}}{\partial y}=\frac{k}{m}\left(v-v_{p}\right)
\end{gathered}
$$




$$
\frac{\partial}{\partial x}\left(\rho_{p} u_{p}\right)+\frac{\partial}{\partial y}\left(\rho_{p} v_{p}\right)=0
$$

where $(\mathrm{u}, \mathrm{v})$ and $\left(\mathrm{u}_{p}, \mathrm{v}_{p}\right)$ denote velocity components of the fluid and dust particle phases along $\mathrm{x}$ and $\mathrm{y}$ directions. Furthermore, are the density of the fluid, dynamic viscosity of the fluid, density of the particle phase, number density of dust particles, $\mathrm{B}_{0}$ is the uniform magnetic field,is the density ratio, $\mathrm{K}$ is the Stokes drag coefficient $\left(\mathrm{K}=6 \prod \mu r\right)$ and $\mathrm{r}$ is the radius of dust particle.

The boundary conditions applicable to the flow problem are

$$
u=U_{w}(x), \quad v=0 \quad \text { at } y=0
$$

$$
u \rightarrow U(x), u_{p} \rightarrow U(x), v_{p} \rightarrow v, \rho_{p} \rightarrow \rho \omega \text { as } y \rightarrow \infty
$$

By employing the generalized Bernoulli's equation, in the free-stream $\mathrm{U}(\mathrm{x})=\mathrm{bx}$ the equation (2) transforms to

$$
U \frac{d u}{d x}+\frac{\sigma B_{0}^{2} U}{\rho}=-\frac{1}{\rho} \frac{d p}{d x}
$$

Substituting (7) into (2)

$$
u \frac{\partial u}{\partial x}+v \frac{\partial u}{\partial y}=\frac{\mu}{\rho} \frac{\partial^{2} u}{\partial v^{2}}+U \frac{d u}{d x}+\frac{K N}{\rho}\left(u_{p}-u\right)-\frac{\sigma B_{0}^{2}}{\rho}(U-u)
$$

Introducing the following similarity transformations:

$$
\begin{aligned}
& \zeta=\left(\frac{u_{w}}{v x}\right)^{1 / 2} y, \quad \psi=x(v a)^{1 / 2} f(\zeta), u_{p}=\operatorname{ax} F(\zeta), \\
& v_{p}=(v a)^{1 / 2} G(\zeta), \quad \rho_{r}=H(\zeta),
\end{aligned}
$$

where $\psi$ is the stream function defined by the relation:

$$
u=\frac{\partial \psi}{\partial y}, v=-\frac{\partial \psi}{\partial x}
$$

One can observe continuity equation is satisfied and equations (8), (3), (5), (9) take the following forms:

$$
\begin{gathered}
f^{\prime \prime \prime}-f^{\prime 2}+f f^{\prime \prime}+l \beta H\left[F-f^{\prime}\right]+\lambda^{2}-M\left[f^{\prime}-\lambda\right]=0 \\
G F^{\prime}+F^{2}+\beta\left[F-f^{\prime}\right]=0 \\
G G^{\prime}+\beta[f+G]=0 \\
H F+H G^{\prime}+G H^{\prime}=0
\end{gathered}
$$

The transformed boundary conditions are:

$$
f(\zeta)=0, f^{\prime}(\zeta)=1, \text { at } \zeta=0,
$$

$f^{\prime}(\zeta)=0, F(\zeta)=0, G(\zeta)=-f(\zeta), H(\zeta)=\omega$ as $\zeta \rightarrow \infty$

Here prime indicates order of differentiation with respect to $\zeta$ and $\mathrm{M}=\frac{\sigma B_{0}^{2}}{\rho a}$ is the magnetic field parameter, $l=\frac{m N}{\rho}$ is the dust particles mass concentration parameter, $\lambda=\frac{b}{a}$ is the ratio of the free stream velocity parameter to the stretching sheet parameter, $\tau=\frac{m}{k}$ is the relaxation time of the dust particles, i.e., the time required by a dust particle to adjust its velocity relative to the fluid, $\beta=\frac{1}{a \tau}$ is the fluid particle interaction parameter, $\rho_{r}=\frac{\rho_{p}}{\rho}$ is the relative density.

\subsection{Heat transfer analysis}

The boundary layer heat equations for both fluid and particle phase in the presence of Cattaneo -Christov heat flux are given by

$$
\begin{gathered}
u \frac{\partial T}{\partial x}+v \frac{\partial T}{\partial y}+\lambda_{1}\left(u^{2} \frac{\partial^{2} T}{\partial x^{2}}+v^{2} \frac{\partial^{2} T}{\partial y^{2}}+\left(u \frac{\partial u}{\partial x}+v \frac{\partial u}{\partial y}\right) \frac{\partial T}{\partial x}\right. \\
\left.+2 u v \frac{\partial^{2} T}{\partial x \partial y}+\left(u \frac{\partial v}{\partial x}+v \frac{\partial v}{\partial y}\right) \frac{\partial T}{\partial y}\right)=\frac{k}{\rho c_{p}} \frac{\partial^{2} T}{\partial y^{2}} \\
+\frac{N c_{p}}{\tau_{T}}\left(T_{p}-T\right)+\frac{N}{\tau_{v} \rho c_{p}}\left(u_{p}-u\right)^{2} \\
u_{p} \frac{\partial T_{p}}{\partial x}+v_{p} \frac{\partial T_{p}}{\partial y}=\frac{c_{p}}{c_{m} \tau_{T}}\left(T-T_{p}\right)
\end{gathered}
$$

Here $\mathrm{T}$ and $\mathrm{T}_{p}$ represents temperature of the fluid and dust particles, $\mathrm{C}_{m}$ and $\mathrm{C}_{p}$ are specific heat of dust particles and fluid, $\tau_{v}$ is the relaxation time of dust phase, $\tau_{T}$ indicates the thermal equilibrium time i.e., time required by the dust cloud to adjust it temperature to that of fluid, $\mathrm{k}$ is the thermal conductivity of the fluid and $\lambda$ is the thermal relaxation time.

The solutions of the equations (15) and (16) depends on the nature of the prescribed boundary condition

1. Prescribed Wall temperature

2. Prescribed heat flux

\section{Prescribed Wall temperature (PWT)}

In this heating process we employ the following wall temperature boundary condition:

$$
\begin{gathered}
T=T_{w} \text { at } y \rightarrow 0 \\
T \rightarrow T_{\infty}, T p \rightarrow T_{\infty} \text { as } y \rightarrow \infty,
\end{gathered}
$$

Where $\mathrm{T}_{w}$ denote the temperature at the wall and $T_{\infty}$ denote the temperature far away from the stretching surface, $\theta(\zeta)$ and $\theta_{p}(\zeta)$ are the dimensionless variables for the temperatures 
Where

$$
\begin{gathered}
T=T_{\infty}+\left(T_{w}-T_{\infty}\right) \theta(\zeta) \\
T_{p}=T_{\infty}+\left(T_{p}-T_{\infty}\right) \theta_{p}(\zeta)
\end{gathered}
$$

Using (17) and (18) in (15) and (16) we get

$$
\begin{aligned}
& \frac{1}{\operatorname{Pr}} \theta^{\prime \prime}(\varsigma)+f(\varsigma) \theta^{\prime}(\varsigma)-y\left(f(\varsigma) f^{\prime}(\varsigma) \theta^{\prime}(\varsigma)+f^{2}(\varsigma) \theta^{\prime \prime}(\varsigma)\right) \\
& +\frac{N}{\rho a \tau_{T}}\left(\theta_{p}(\varsigma)-\theta(\varsigma)\right)+\frac{N E_{c}}{\rho \tau_{v}}\left(F(\varsigma)-f^{\prime}(\varsigma)\right)^{2}=0
\end{aligned}
$$

$$
2 F(\varsigma) \theta_{p}(\varsigma)+G(\varsigma) \theta_{p}^{\prime}(\varsigma)+\frac{c_{p}}{a c_{m} \tau_{T}}\left(\theta_{p}(\varsigma)-\theta(\varsigma)\right)=0
$$

Where $\operatorname{Pr}=\frac{\mu c_{p}}{k}$ the Prandl number, $y=\lambda_{1} a$ the thermal relaxation time, $E c=\frac{c l^{2}}{A c_{p}}$ is the Eckert number.

Corresponding thermal boundary conditions are

$$
\begin{gathered}
\theta(\zeta)=1 \text { at } \zeta=0 \\
\theta(\zeta) \rightarrow 0, \quad \theta_{p}(\zeta) \rightarrow 0 \quad \text { as } \zeta \rightarrow \infty,
\end{gathered}
$$

\section{Prescribed heat flux (PHF case)}

In PHF-Case heat flux on the wall surface is considered as

$$
\begin{gathered}
-K^{\star} \frac{\partial T}{\partial y}=q_{w}=D\left(\frac{x}{l}\right)^{2} \text { at } y=0 \\
T \rightarrow T_{\infty}, \quad T_{p} \rightarrow T_{\infty} \text { as } y \rightarrow \infty
\end{gathered}
$$

Where $\mathrm{D}$ is a constant and $T_{w}-T_{\infty}=\frac{D}{K^{\star}}\left(\frac{x}{l}\right)^{2} \sqrt{\frac{v}{l}}$.

Dimensionless temperature variables in case of clean fluid temperature $g(\zeta)$ and dust fluid temperature $g_{p}(\zeta)$ as

$$
\begin{gathered}
T=T_{\infty}+\left(T_{w}-T_{\infty}\right) g(\zeta) \\
T_{p}=T_{\infty}+\left(T_{w}-T_{\infty}\right) g_{p}(\zeta)
\end{gathered}
$$

Using (22) and (23) in (15) and (16) we get

$$
\begin{aligned}
& \frac{1}{\operatorname{Pr}^{\prime}} g^{\prime \prime}+f g^{\prime}-y\left(f f^{\prime} g^{\prime}+f^{2} g^{\prime \prime}\right)+\frac{N}{\rho a \tau_{T}}\left(g_{p}-g\right) \\
& +\frac{N E_{c}}{\rho \tau_{v}}\left(F-f^{\prime}\right)^{2}=0 \\
& 2 F g_{p}+G g_{p}^{\prime}+\frac{c_{p}}{a c_{m} \tau_{T}}\left(g_{p}-g\right)=0
\end{aligned}
$$

Where $E c=\frac{k l^{2} c^{3 / 2}}{D c_{p} v^{1 / 2}}$ is the Eckert number.

The transformed boundary conditions are:

$$
\begin{gathered}
g^{\prime}=-1 \text { at } \zeta=0 \\
g(\zeta) \rightarrow 0, \quad g_{p} \rightarrow 0 \text { as } \zeta \rightarrow \infty
\end{gathered}
$$

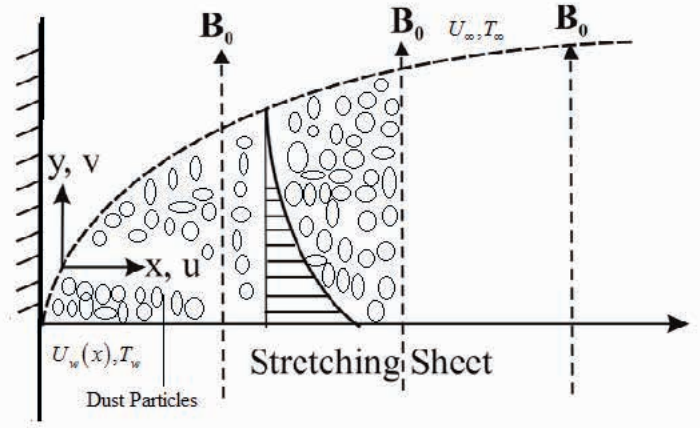

Fig. 1: The physical geometry of flow configuration

\section{Results and Discussion}

To have a better understanding of the physical model, equations (10) to (13) , (19), (20) and (24), (25) with the boundary conditions (14), (21) and (26) are solved numerically by using Runge Kutta $4^{\text {th }}$ order with shooting technique. Numerical solutions for the dimensionless velocity, temperature profiles along with local Nusselt number and skin friction factor are demonstrated in graphical and tabular form. We have considered the non- dimensional parameters $1=0.3, \beta=0.3, \mathrm{M}=0.3, y=0.1, \mathrm{~N}=0.2, \rho=0.5$, $\mathrm{a}=1, \tau_{T}=0.5, \tau_{v}=0.5, \mathrm{Ec}=0.5, \mathrm{C}_{m}=0.2, \mathrm{C}_{p}=0.2, \omega=0.2$, $\lambda=0.1$, Pr $=4$ for obtaining numerical solutions throughout the study apart from the variations in the corresponding tables and figures.

\subsection{Momentum Boundary layer analysis}

Figures $2 \mathrm{a}$ and $2 \mathrm{~b}$ illustrates the influence of nondimensional fluid particle interaction parameter $(\beta)$ on the hydrodynamic boundary layer of both fluid and dust phase. It is found that accelerating values of fluid particle interaction parameter $\beta$ decay the velocity profiles of fluid and dust phase. Moreover, it is observed that the fluid particle interaction parameter effectively reduces the fluid velocity in PWT case than PHF case. Whereas in case of dust phase velocity profiles behave similar in both the PWT and PHF case. Figs $3 a$ and $3 b$ displays the influence of magnetic parameter on velocity profiles of fluid and dust phase. It is observed that velocity profiles decay with the increasing values of magnetic field parameter in both fluid and dust phase. Physically, fluid motion is restricted with the increasing values of $\mathrm{M}$ due the drag force developed by Lorentz force. Nature of velocity profiles is similar in both PWT and PHF case in case of dust fluid. Figures 4a, 4b presents the effect of $\lambda$-the ratio of free stream velocity pa- 


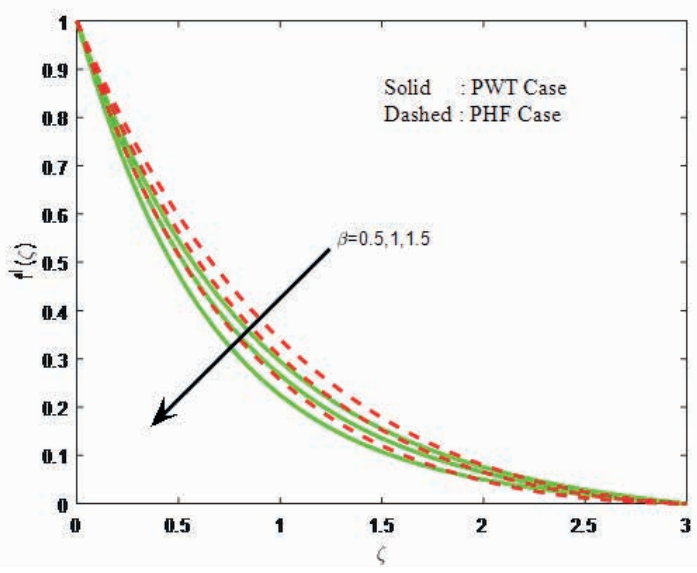

(a)

Fig. 2: a,b) Velocity profiles with varying fluid particle interaction parameter $\beta$.

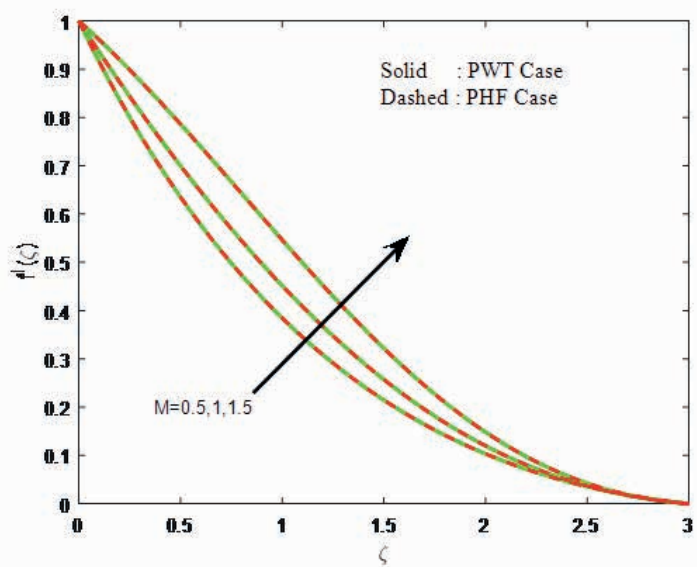

(a)

Fig. 3: a,b) Velocity profiles with varying magnetic parameter (M).

Table 1: Validation of the local Nusselt number $\left(-\theta^{\prime}(0)\right)$ for the case of $\lambda=0, \beta=0, E c=0, y=0$.

\begin{tabular}{lllll}
\hline $\operatorname{Pr}$ & Grubka and Bobba [8] & Abel and Mahesha [12] & Ramesh et al. [23] & Present \\
\hline 0.72 & 1.0885 & 1.0885 & 1.0885 & 1.0885 \\
1.0 & 1.3333 & 1.3333 & 1.3333 & 1.33321 \\
3.0 & 2.5097 & - & 2.5097 & 2.509692 \\
10.0 & 4.7969 & 4.7968 & 4.7968 & 4.79682 \\
\hline
\end{tabular}

rameter to stretching velocity parameter. We observe that dust phase velocity is an increasing function of $\lambda$ but an opposite outcome is observed in fluid phase. But the nature of velocity profiles is similar in both PWT and PHF case for fluid and dust phase.

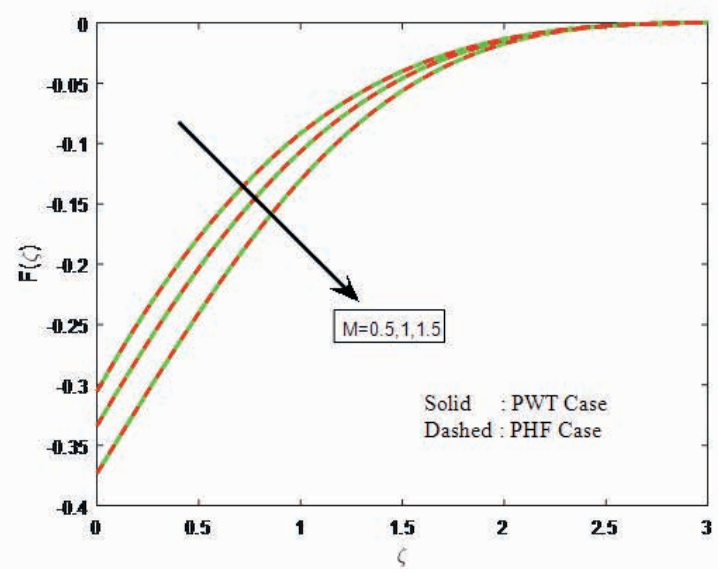

(b)

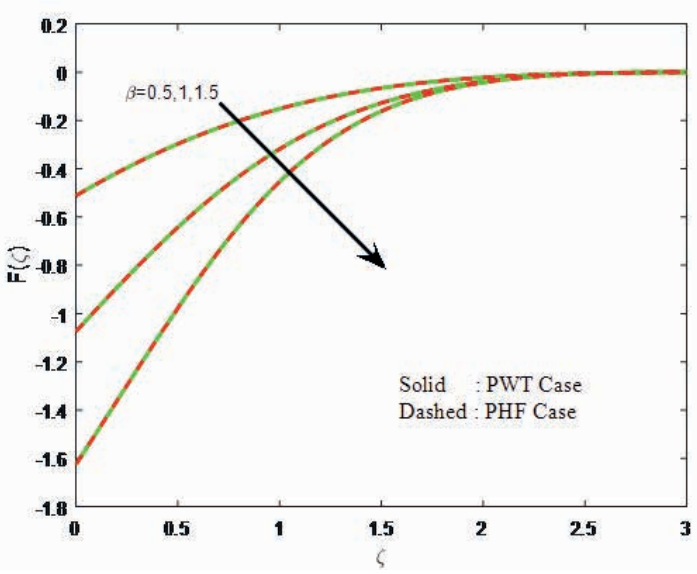

(b) 


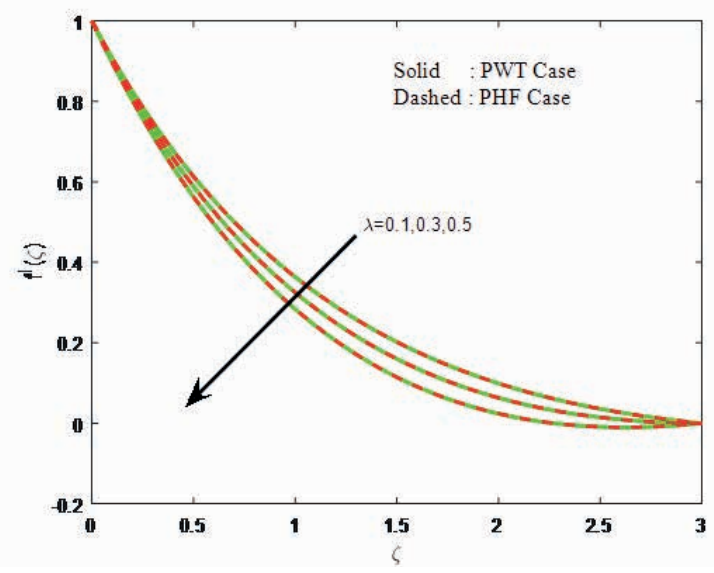

(a)

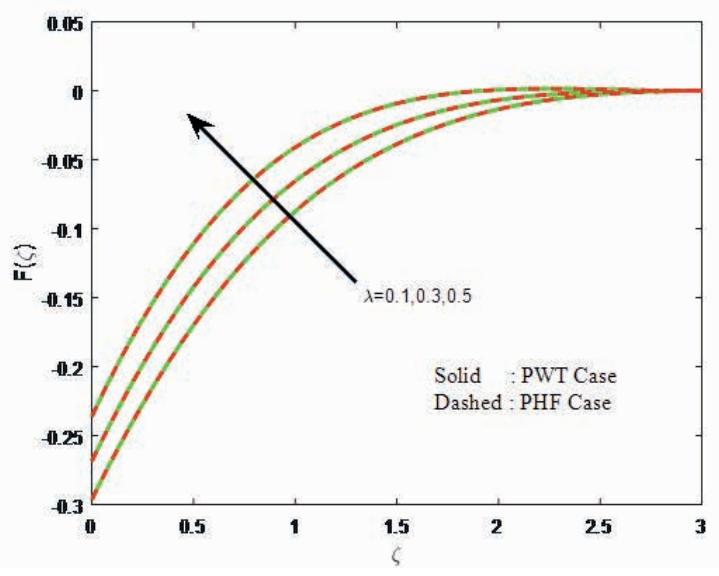

(b)

Fig. 4: a,b) Velocity profiles with varying parameter $(\lambda)$ on the fluid and dust phase.

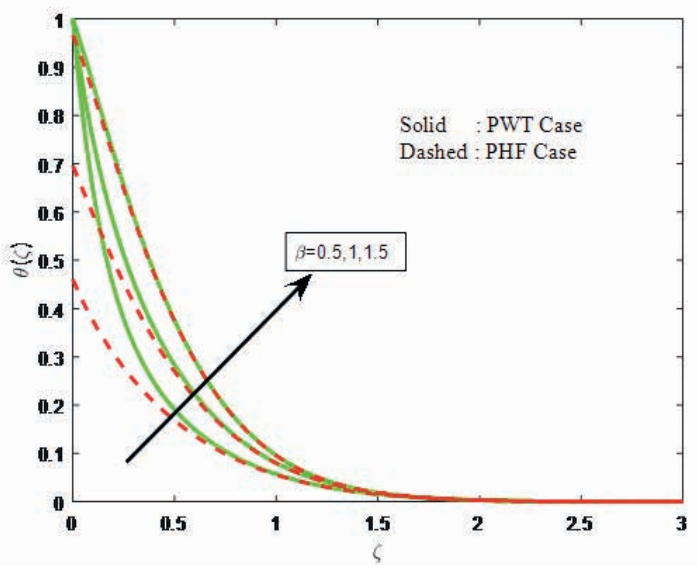

(a)

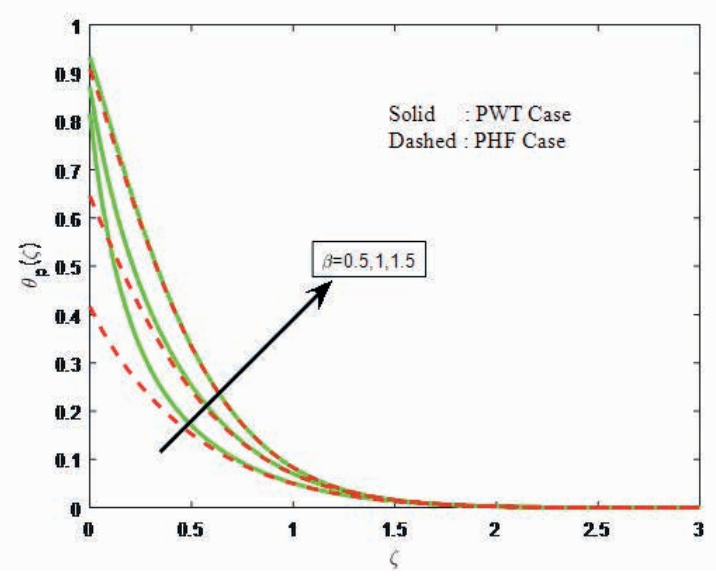

(b)

Fig. 5: a,b) Temperature profiles with varying fluid particle interaction parameter $(\beta)$.

phase. With increase in $\beta$ there is a sharp growth in wall slope of temperature function in both the PHF and PWT case for both the fluids (Clean and Dust phase).

Figures $6 \mathrm{a}, 6 \mathrm{~b}$ the effect of magnetic parameter on thermal boundary layers is displayed. It is observed that accelerating values of Magnetic field parameter enhance the temperature field in case of both kinds of fluid (Clean and Dust fluid). This is due to Lorentz force. Moreover we can observe magnetic field effectively controls the thermal field of the flow in PWT case when compared with PHF case. Figures $7 \mathrm{a}, 7 \mathrm{~b}$ portray the effect of thermal relaxation time on temperature profiles of fluid and dust phase. We notice increasing values of thermal relaxation time corresponds to low temperature. Increasing values of thermal relaxation time enhance the gap between the fluid parti- cles due to which they require large time to bring heat to their neighboring particles. One can noticed that the influence of thermal relaxation time is more effective over a PHF case than PWT case. The influence of Eckert number on temperature profiles of fluid and dust phase are displayed in Figures $8 \mathrm{a}$ and $8 \mathrm{~b}$. A rise in values of Ec enhances the thermal boundary layer in case of fluid and dust phase. Eckert number relates the relationship between Kinetic energy in the flow to the enthalpy. It embodies in converting Kinetic energy to internal energy by work done against the viscous fluid stresses. It is clear that rising viscous dissipation enhances in the temperature and thermal boundary layer thickness. It is also observed that temperature in PWT case is higher than PHF case. The effect of $\lambda$ on temperature profiles are plotted in Figures $9 \mathrm{a}$ and $9 \mathrm{~b}$ for 


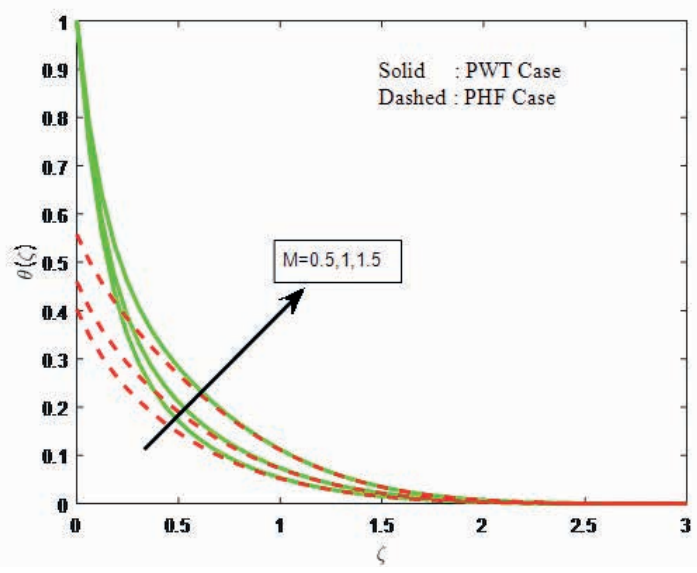

(a)

Fig. 6: a,b) Temperature profiles with varying magnetic parameter (M).

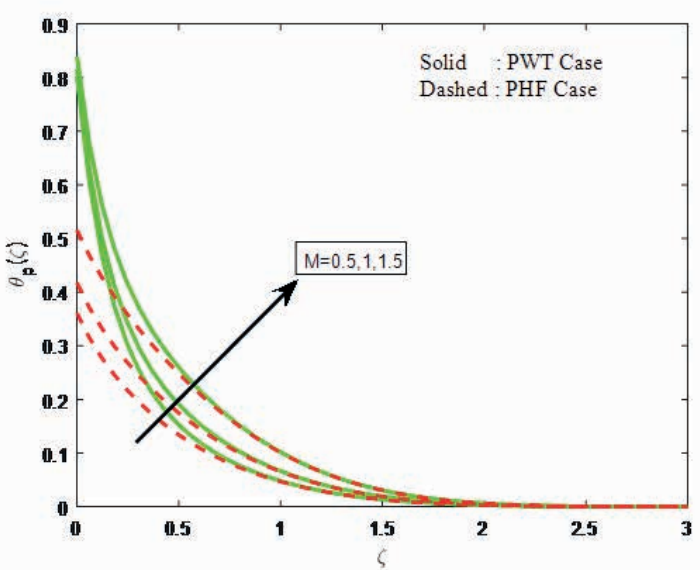

(b)

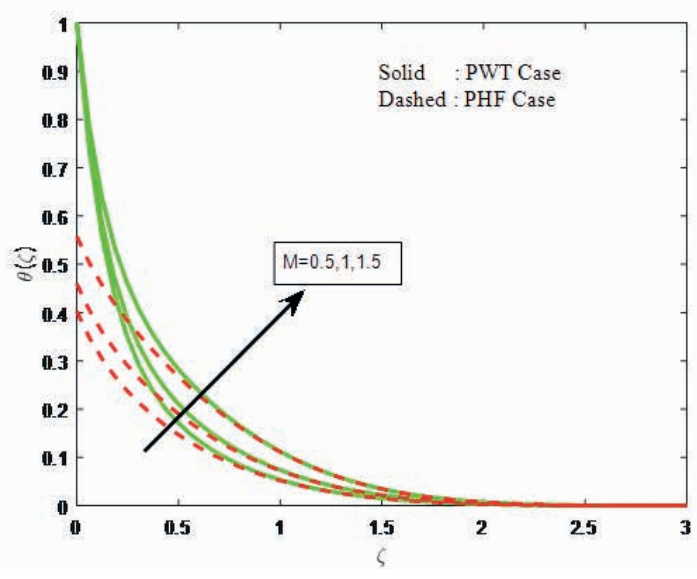

(a)

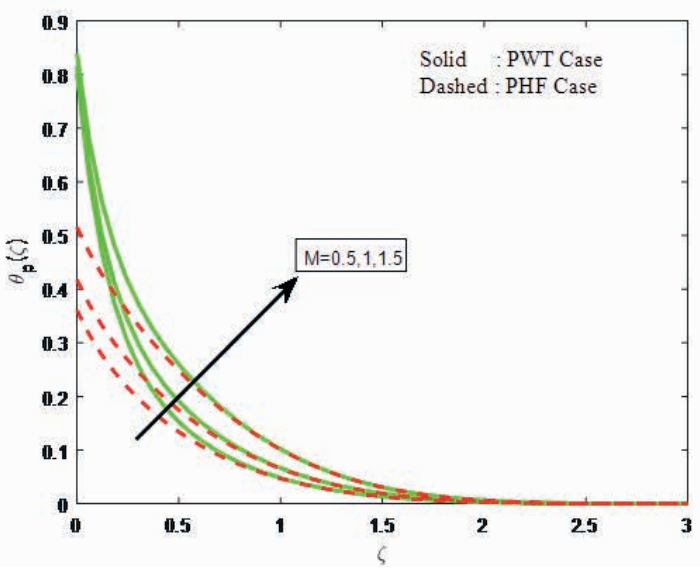

(b)

Fig. 7: a,b) Temperature profiles with varying thermal relaxation time $(y)$.

both the fluids (Clean and Dust) and boundary conditions (PWT and PHF cases). Deterioration in both temperature profiles can be observed with increasing values of $\lambda$. This may happen due to very low values of free stream velocity to stretching ration velocity.

Table 2 demonstrates the variation of local Nusselt number and friction coefficients for various values of nondimensional governing parameters. The particle interaction parameter increases the friction factor in both cases (PWT and PHF) and suppresses the local Nusselt number, this is due to dominance of higher particle interaction. Whereas, similarly opposite phenomena was observed in the presence of thermal relaxation parameter. The cause for this trend is when we incorporate thermal relaxation the surrounding particles are highly motivated. Due to this we saw enhancement in rate of heat transfer. Both the friction factor and local Nusselt number are minimized with the rising values of the Eckert number and magnetic field parameters. The opposite behavior of $M$ was observed in $\lambda$. The rising values of $\lambda$ increases the both Nusselt and friction factor values. Table 1 shows the validation of present solutions with already existing studies under some limited condition of Grubka and Bobba [8], Abel and Mahesha [12] and Ramesh et al. [23]. It is found that raising the values of prandtl number improves the local nusselt number. 


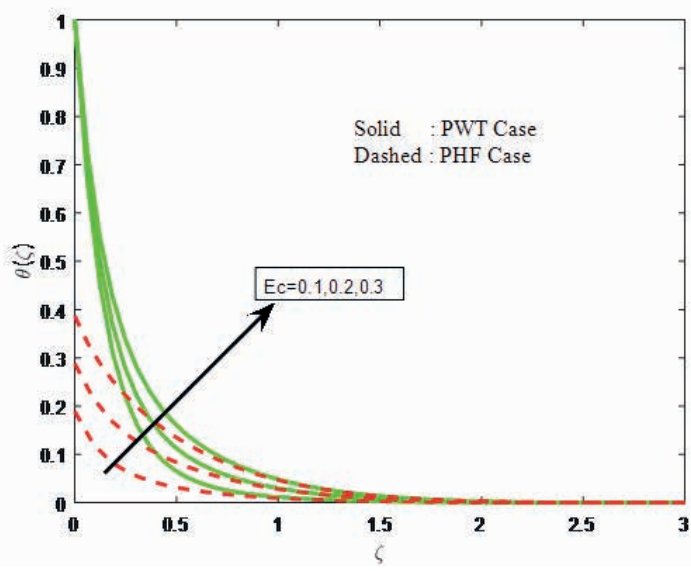

(a)

Fig. 8: a,b) Temperature profiles with varying Eckert number (Ec).

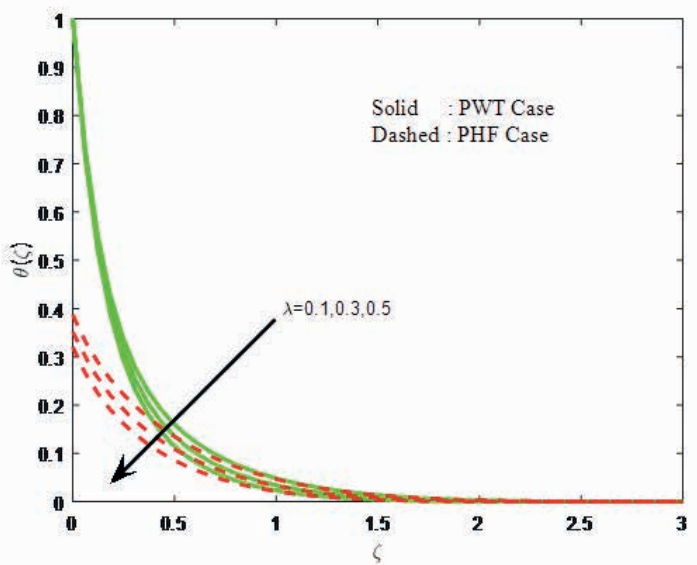

(a)

Fig. 9: a,b) Temperature profiles with varying parameter $(\lambda)$.

\section{Conclusions}

In the present study, Cattaneo-Christov heat flux theory is employed in thermal equation of the flow over a stretching sheet, the observation of the present study is as follows:

1. Dust phase velocity profiles shows similar behavior in both PWT and PHF case for all the parameters considered in the study.

2. For higher value of fluid particle interaction parameter thermal boundary layer in both PWT and PHF case for fluid and dust phase are coinciding.

3. Momentum boundary layer thickness is exhibiting similar behavior in both PWT and PHF case.

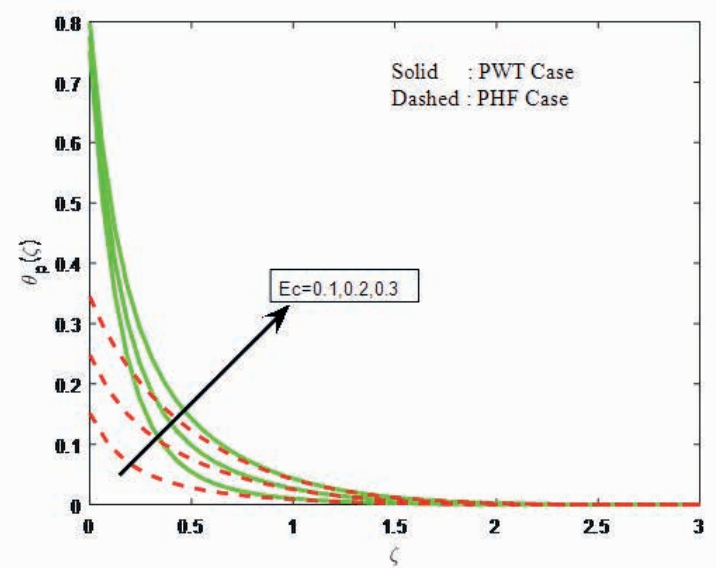

(b)

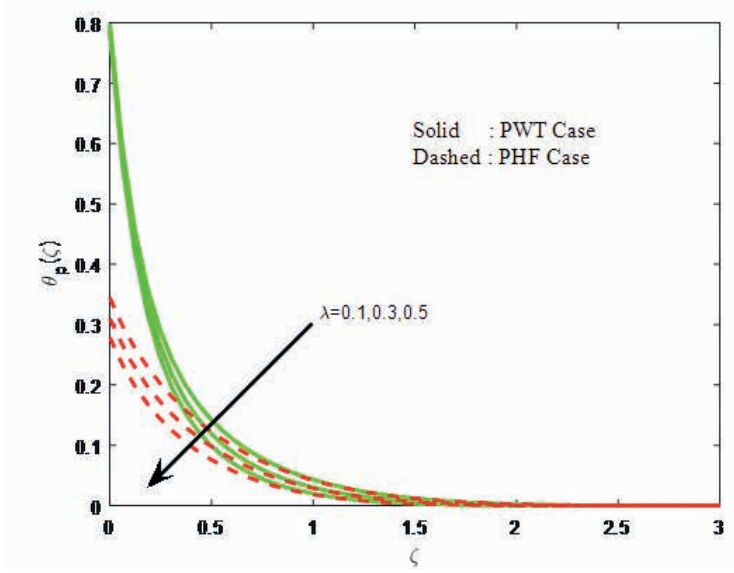

(b)

4. Increasing values of thermal relaxation time exhibits the similar thermal boundary layer in case of both fluid and dust phase for PHF case. Whereas for both the fluids thermal relaxation time reduce the temperature profiles.

5. Thermal boundary layer enhances with the increase in Eckert number in PWT and PHF case for both the fluid phase. Moreover Eckert number increases flow of heat faster in PWT case than PHF case.

6. For Effective cooling of the stretching sheet the PHF boundary condition is better suited.

7. There is no change in wall temperature gradient for the parameters considered in the study in both PWT and PHF case. 
Table 2: Variations in Skin friction coefficient, local Nusselt number in Prescribed Wall temperature (PWT) case

\begin{tabular}{|c|c|c|c|c|c|c|c|c|}
\hline \multirow{2}{*}{ B } & \multirow{2}{*}{ M } & \multirow{2}{*}{$y$} & \multirow{2}{*}{$\lambda$} & \multirow{2}{*}{ Ec } & \multicolumn{2}{|c|}{ - Skin friction coefficient } & \multicolumn{2}{|c|}{-Local Nusselt number } \\
\hline & & & & & PWT Case & PHF Case & PWT Case & PHF Case \\
\hline 0.5 & & & & & 1.007482 & 1.007484 & 4.856752 & -0.460041 \\
\hline 1 & & & & & 1.187456 & 1.187455 & 3.154858 & -0.695699 \\
\hline \multirow[t]{13}{*}{1.5} & & & & & 1.430314 & 1.430315 & 1.230223 & -0.967114 \\
\hline & 0.5 & & & & 0.876466 & 0.876466 & 5.293511 & -0.402675 \\
\hline & 1 & & & & 0.652593 & 0.652592 & 4.926100 & -0.459749 \\
\hline & 1.5 & & & & 0.378598 & 0.378599 & 4.258451 & -0.557908 \\
\hline & & 0 & & & 0.955845 & 0.955844 & 3.837020 & -0.433715 \\
\hline & & 0.1 & & & 0.955845 & 0.955844 & 5.393539 & -0.386446 \\
\hline & & 0.2 & & & 0.955845 & 0.955845 & 11.004039 & -0.330518 \\
\hline & & & 0.1 & & 0.955845 & 0.955844 & 5.393539 & -0.386446 \\
\hline & & & 0.3 & & 1.018327 & 1.018327 & 5.626020 & -0.351645 \\
\hline & & & 0.5 & & 1.083294 & 1.083294 & 5.833769 & -0.319970 \\
\hline & & & & 0.1 & 0.955845 & 0.955845 & 6.807301 & -0.189008 \\
\hline & & & & 0.2 & 0.955845 & 0.955845 & 6.100420 & -0.287725 \\
\hline & & & & 0.3 & 0.955845 & 0.955844 & 5.393539 & -0.386446 \\
\hline
\end{tabular}

\section{References}

[1] B.C.Sakiadis, Boundary layer behavior on continuous solid surface, A.I.Ch.E. J,7(1961) 26-28

[2] L.J.Crane, Flow past a stretching sheet, Z .Angew. Math .Phys. (ZAMP), 21(1970)645-647.

[3] Emad M.Abo-Eladahab, Mohamed A.El.Aziz, Blowing / suction effect on haydr-magnetic heat transfer by mixed convection from an inclined continuously stretching surface with internal heat generation/absorption ,Int. J. Therm. Sci, (2004) 709-719.

[4] P.G Saffman, On the stability of laminar flow of a dusty gas, J. Fluid Mechs, 13(1962) 120-128.

[5] N.Dutta, S.K. Mishra, Boundary layer flow of a dusty fluid over a semi-infinite flat plate, Acta Mechanica, 42(1982)71-83.

[6] V.M Agranat, (1988) Effect of pressure gradient on friction and heat transfer in a dusty boundary layer, Fluid Dyn 23(5)(1988)729-732.

[7] K.Vajravelu, J Nayfeh, Hydromagnetic flow of a dusty fluid over stretching sheet, Int J Nonlinear Mech ,27(1992)937-945.

[8] L.J.Grubka, K.M. Bobba, Heat transfer characteristics of a continuous stretching surface with variable temperature, ASME J Heat Transfer 107(1985)248-250.

[9] A.J. Chamkha, Unsteady MHD convective heat and mass transfer past a semi- infinite vertical permeable moving plate with heat absorption, Int. J. of engineering science,42(2004) ) 217230.

[10] A.Aziz, A similarity solution for laminar thermal boundary layer over a flat plate with a convective surface boundary condition, Commun Nonlinear Sci Numer Simul, 14(2009)1064-1068.

[11] Hermann Schlichting, H. (1968) Boundary layer theory. McGraw-Hill

[12] M.S.Abel, N Mahesha, Heat transfer in MHD Viscoelastic fluid flow over a stretching sheet with variable thermal conductivity, non-uniform heat source and radiation, App. Math. Model 32 (2008) $1965-1983$.

[13] C.S.K.Raju, N.Sandeep, C.Sulochana, V.Sugunamma, Effects of aligned magneticfield and radiation on the flow of ferro fluids over a flat plate with non-uniform heat source/sink, Int.J.Sci and Eng. 8(2), 151-158, 2015.

[14] M.A Ezzat, A.A. El-Bary, M.M.Morsey, Space approach to the hydro-magnetic flow of a dusty fluid through a porous medium, Computers and Mathematics with applications, 59(2010) 2868-2879.

[15] C.S.K.Raju, N.Sandeep, C.Sulochana, M.Jayachandra Babu, Dual solutions of MHD boundary layer flow past an exponentially stretching sheet with non-uniform heat source/sink, Journal of Applied Fluid Mechanics, 9 (2016) 555-563.

[16] B.J.Gireesha, G.S.Roopa ,C.S. Bag ewadi, (2012) Effect of viscous dissipation and heat source on flow and heat transfer of dusty fluid over unsteady stretching sheet, Appl Math Mech 33 (2012)1001-1014.

[17] B.J.Gireesha, A.J.Chamkha, C.S..Vishalakshmi, C.S.Bagewadi ,Applied Mathematical Modeling, 36(2012) $683-701$

[18] B.J.Gireesha, B.Mahanthes, M.M Rashidi, MHD Boundary layer Heat and mass transfer of a chemically reacting casson fluid over a permeable stretching surface with non-uniform heat source / sink, Int. J. Industrial Mathematics, 7(2015)247260

[19] B.J.Gireesha, B.Mahanthesh, I.S..Shivakumara ,K.M. Eshwarappa, Melting heat transfer in boundary layer stagnation point flow of nanofluid toward a stretching sheet with induced magnetic field., http://dx.doi.org/10.1016/j.jestch. 2015.07.012/

[20] B.J.Gireesha, B.Mahanthesh, R.S.R.Gorla, Suspended particle effect on nanofluid boundary layer flow past a stretching surface, Journal of nanofluid, 3(2014) 267-277.

[21] Sadia Siddiqa, M. Anwar Hossain Hossain, Suvash C.Saha , Two-phase natural convection flow of a dusty fluid, Int.J. of Numerical Methods for Heat and Fluid Flow ,25,7(2014)15421556.

[22] G.K.Ramesh,B.J.Gireesha, Rama Subba Reddy Gorla, Boundary layer flow past a stretching sheet with fluid -particle suspension and convective boundary condition , Heat Mass Transfer DOI 10.1007/s00231-014-1477-z.

[23] G.K.Ramesh, B.J.Gireesha, C.S.Bagewadi, Stagnation point flow of a dusty fluid towards a stretching sheet with radia- 
tion,Afr.Mat,. 25(2014) 237-249.

[24] C.S.K. Raju, N. Sandeep, A. Malvandi, Free convective heat and mass transfer of MHD non-Newtonian nanofluids over a cone in the presence of non-uniform heat source/sink, Journal of Molecular Liquids. (2016). doi:10.1016/j.molliq.2016.05.078.

[25] Sugunamma V, Ramana Reddy J. V., Sandeep N, Raju C.S. K, Chemically reacting MHD dusty nanofluid flow over a vertical cone with non-uniform heat source/sink, Walailak Journal of Science and Technology, in press, (2016) http://wjst.wu.ac.th/index.php/wjst/article/view/1906.

[26] J.B.J.Fourier, Theorie Analytique De La Chaleur,Paris.

[27] C.Cattaneo,Sulla Conduzionedelcalore,Atti del Seminario Matematico e Fisico dell Universita di Modena e Reggio Emilia 3(1948) 83-101.
[28] C.I. Christov, On frame indifferent formulation of the MaxwellCattaneo model of finite speed heat conduction, Mechanics Research Communications 36(2009)481-486.

[29] S.Han, L.Zheng,C.Li, and X. Zhang, Coupled flow and heat transfer in viscoelastic fluid with Cattaneo-Christov heat flux model, Applied Mathematics Letters 38(2014)87-93.

[30] Junaid Ahmad Khan, M.Mustafa,T.Hayat and A.Alsaedi, Numerical Study of Cattaneo -Christov Heat Flux Model for Viscoelastic Flow Due to an Exponentially Stretching Surface,PLOS One,10(9)(2015)doi:10.1371/journal.pone.0137363. 